$\begin{array}{r}\text { Phinisi Integration Review } \\ \text { Vol. 1, No.2, Agustus 2018 Hal 128-132 } \\ \text { Website: } \underline{\text { http://ojs.unm.ac.id/pir }} \\ \hline\end{array}$

\title{
Makna Simbolik Tradisi Ogoh-Ogoh Dalam Rangkaian Perayaan Hari Raya Nyepi Di Desa Pepuro Barat Kecamatan Wotu Kabupaten Luwu Timur
}

\author{
Kadek Winarta \\ Pendidikan Ilmu Pengetahuan Sosial, Universitas Negeri Makassar \\ Email: kadekwinarta904@gmail.com
}

\begin{abstract}
Abstrak. Penelitian bertujuan mendeskripsikan latar belakang tradisi Ogoh-ogoh dijadikan rangkaian dari perayaan hari raya Nyepi di Desa Pepuro Barat Kecamatan Wotu Kabupaten Luwu Timur, eksistensi tradisi Ogoh-ogoh dalam rangkaian perayaan hari raya Nyepi di Desa Pepuro Barat Kecamatan Wotu Kabupaten Luwu Timur, dan makna simbolik tradisi Ogoh-ogoh dalam rangkaian perayaan hari raya Nyepi di Desa Pepuro Barat Kecamatan Wotu Kabupaten Luwu Timur. Jenis penelitian ini adalah deskriptif kualitatif. Teknik pengumpulan data yang digunakan yaitu observasi, wawancara dan dokumentasi. Teknik analisis data yang digunakan menggunakan analisis deskriptif kualitatif dengan penentuan informan melalui teknik purposive sampling. Hasil penelitian menunjukan bahwa Ogoh-ogoh dijadikan rangkaian dari pada perayaan hari raya Nyepi di Desa Pepuro Barat, karena Ogoh-ogoh dapat merepresentasikan segala kegiatan-kegiatan yang berhubungan dengan ritual keagamaan masyarakat suku Bali yang ada di Desa Pepuro Barat, terkhususnya perayaan hari raya Nyepi tersebut. Ogoh-ogoh dapat mempertahankan eksistensinya di Desa Pepuro Barat, karena Ogoh-ogoh yang dibuat memiliki daya tarik yang kuat seperti memberikan kemeriahan, keseruan, keramaian, kesemarakan dan dibuat berdasarkan fenomena yang terjadi pada masyarakat Pepuro Barat. Ogoh-ogoh bagi masyarakat suku Bali yang ada di Desa Pepuro Barat bermakna sebagai keseimbangan yang terjadi dalam masyarakat. Keseimbangan itu meliputi aspek sifat seperti kebaikan dan keburukan, kedewataan dan kebhutakalaan, serta persatuan dan konflik. Oleh karena itu, berdasarkan temuan yang telah diperoleh disarankan agar masyarakat Suku Bali yang ada di Desa Pepuro Barat, selalu bijak mengambil sikap/keputusan yang berkaitan dengan kelestarian kebudayaan, terutama tradisi Ogohogoh. Sehingga nantinya tradisi Ogoh-ogoh dapat dinikmati generasi selanjutnya dan tentunya tetap berpedoman pada nilai-nilai yang ditanamkan sebelumnya.
\end{abstract}

Kata Kunci: Makna, Ogoh-ogoh, Pepuro Barat.

Ini adalah artikel dengan akses terbuka dibawah licenci CC BY-NC-4.0

(https://creativecommons.org/licenses/by-nc/4.0/)

\section{PENDAHULUAN}

Indonesia adalah negara kepulauan, yang secara geografis terletak diantara Benua Australia dan Asia. Indonesia berada dalam daerah srategis di kawasan Asia Tenggara sebagai jalur pelayaran dan perdagangan Internasional sehingga pada gilirannya menjalani proses pertemuan dan pengaruh budaya asing, yakni pengaruh kebudayaan India (Hindu-Budha), kebudayaan Islam dan kebudayaan Barat (Rahim \& Madjid, 2012: 94) 
Hal ini juga berdampak pula pada semakin majemuknya kebudayaan masyarakat Indonesia. Kemajemukan budaya masyarakat Indonesia, meliputi beranekaragam perbedaan, yaitu; kelompok etnik, agama, daerah asal, dan ras (Agussalim, 2008: 44).

Berdasarkan hasil data Badan Pusat Statistik (BPS) pada tahun 2010, jumlah keseluruhan suku bangsa yang ada di Indonesia mencapai lebih dari 1300 suku bangsa. Dengan perkembangan zaman dan teknologi dewasa ini, tidak dapat dipungkiri bahwa beberapa suku di Indonesia telah mengalami perubahan dalam perkembangannya. Meski diantaranya masih ada pula yang masih bisa menjaga eksistensinya, salah satu diantaranya adalah Suku Bali.

Suku Bali adalah suku yang berasal dari Provinsi Bali dan terletak di Pulau Bali. Suku Bali dikenal sebagai salah satu suku yang ada di Indonesia yang mampu menjaga kelestarian kebudayaannya, ditengah masuknya globalisasi dan berkembang pesatnya teknologi. Covarrubias seorang pengarang dari meksiko yang merangkap sebagai seorang kartunis, mengungkapkan bahwa mustahil pulau ini dapat bertahan sebagai museum hidup sebagaimana yang pernah digagas oleh kaum kolonial. Namun kekhawatiran tersebut rupanya tidak terjadi dan sebaliknya masih tetap dipertahankan (Arcana, 2007: 11).

Kemampuan Suku Bali dalam mempertahankan dan menjaga kebudayaannya tidak hanya berlaku di Pulau Bali saja. Suku Bali yang telah melakukan transmigrasi misalnya, masih tetap mempertahankan kebudayaannya meski sudah berada di luar Pulau Bali. Adapun salah satunya adalah Suku Bali yang ada di Desa Pepuro Barat, Kecamatan Wotu, Kabupaten Luwu Timur, Provinsi Sulawesi Selatan. Suku Bali yang ada di Pepuro Barat merupakan Suku Bali yang telah melakukan transmigrasi dari Pulau Bali sejak tahun 1975.

Tradisi Ogoh-ogoh menjadi salah satu kebudayaan yang kegiatannya bisa dikatakan hampir selalu dilaksanakan dalam masyarakat Suku Bali yang ada di Desa Pepuro Barat. Suku Bali di desa Pepuro Barat, menganut ajaran agama Hindu sama halnya dengan suku Bali yang ada di Bali dan telah mengintegrasikan agama hindu ke dalam kebudayaankebudayaannya (Koentjaraningrat, 2010: 286).

Pada mulanya Ogoh-ogoh merupakan tradisi ngelewang oleh kesenian Ndong-nding yang ada di Kabupaten Gianyar dan Karang
Asem (Widnyani, 2012: 20-21). Selain itu, ada pula yang berpandapat cikal-bakal muncul awalnya Ogoh-ogoh adalah perwujudan raja Jaya Pangus dan putri Kang Cing Wei sebagai Barong Landung.

Menurut Widana (2016) adapula masyarakat yang berpendapat bahwa, kemungkinan Ogoh-ogoh itu dibuat oleh para pengrajin patung yang telah jenuh membuat patung dari batu padas, kayu, maupun bahan lainnya, sehingga timbulah ide untuk membuat patung dari bahan yang ringan supaya bisa diarak dan dipertunjukan.

Perkembangan bentuk Ogoh-ogoh di Bali bisa dikatakan sangat pesat, hal ini dapat dilihat dari bentuk-bentuknya yang tidak hanya berbatas pada satu model. Menurut Widnyani (2012), berdasarkan kajian bentuk dan identifikasi gaya atau ekspresi dari patung Ogoh-ogoh ini, maka terdapat tiga jenis Ogohogoh yaitu, pertama Ogoh-ogoh Bhuta Kala. Ogoh-ogoh jenis ini paling sesuai dengan prosesi ritual Nyepi karena wujudnya yang menyeramkan dengan posturnya yang besar dan tinggi, matanya nampak besar mendelik dan nampak garang. Mulut dan hidungnya besar dan gigi besar mengkilap dan taringnya runcing. Perutnya gendut, kuku panjang dan runcing serta rambutnya gimbal dan berantakan. Kedua, Ogoh-ogoh Wayang. Ogoh-ogoh ini berbentuk tokoh-tokoh dalam pewayangan. Seperti Bima (lambang kebenaran dan kekuatan), Krisna (lambang kebijaksanaan) dan ada juga tokoh Rahwana (lambang keangkaramurkaan) dan yang ketiga, Ogoh-ogoh kontemporer. Untuk jenis Ogoh-ogoh ini, sama sekali tidak mempunyai pakem atau aturan, yang paling penting adalah pesan yang disampaikan kepada masyarakat. Umumnya mengambil gaya yang eksentrik semisal cewek cafe, koruptor dan lainlain.

Berbeda halnya dengan di Pepuro Barat, meski Ogoh-ogoh merupakan Budaya yang dibawa dari Bali namun perkembangannya tidak mengikuti seperti yang ada di Bali. Ogoh-ogoh di Pepuro Barat cenderung mempertahankan bentuk gaya/ekspresi awal dari Ogoh-ogoh yaitu bentuk Bhuta Kala. Dari pertama kali dibuat hingga sekarang bentuk gaya/ekspresinya tidak berubah. Hal ini menjadi sangat menarik, mengingat masyarakat Pepuro Barat adalah suku Bali yang sudah lama melakukan transmigrasi di Pepuro Barat, Namun, dalam hal ini tetap mempertahankan bentuk gaya/ekspresi awal Ogoh-ogoh yang di bawa dari Bali. Sedangkan 
di Bali sendiri, sudah mengalami perubahan bentuk gaya/ekspresi sampai pada yang bertemakan kontemporer/modern. Berdasarkan dari penggambaran realitas di atas, peneliti tertarik untuk mengakajinya secara lebih mendalam, dengan judul "Makna Simbolik Tradisi Ogoh-ogoh dalam Rangkaian Perayaan Hari Raya Nyepi di Desa Pepuro Barat Kecamatan Wotu Kabupaten Luwu Timur”.

\section{METODE}

Jenis penelitian ini adalah deskriptif kualitatif. Teknik pengumpulan data yang digunakan yaitu observasi, wawancara dan dokumentasi. Teknik analisis data yang digunakan dalam penelitian ini adalah menggunakan analisis deskriptif kualitatif dengan penentuan informan melalui teknik purposive sampling atau penentuan melalui beberapa pertimbangan yaitu berstatus sebagai transmigran Suku Bali/lahir di Desa Pepuro Barat, ikut berpartisipasi dalam tradisi Ogohogoh (baik sebagai pembuat, pengarak, maupun pengiring), memiliki jabatan dilihat dari segi agama, adat, desa maupun pemerintahan, dan memiliki umur minimal 17 tahun.

\section{HASIL DAN PEMBAHASAN}

Berdasarkan hasil analisis data, maka hasil penelitian ini dapat dijelaskan sebagai berikut.

Ogoh-Ogoh Menjadi Rangkaian Perayaan Hari Raya Nyepi di Desa Pepuro Barat Kecamatan Wotu Kabupaten Luwu Timur.

Ogoh-ogoh di Pepuro Barat sejak awal telah mengambil gaya/ekspresi menyeramkan, meski dibuat sederhana tetap menonjolkan ekspresi seram tersebut. Terbukti dengan diambilnya bentuk Celuluk sebagai Ogoh-ogoh pertama. Bagi orang Bali, Celuluk adalah perwujudan Leak yang digambarkan sering menakut-nakuti manusia dan memiliki suara yang sangat menyeramkan.

Ogoh-ogoh selalu dibuat menyeramkan karena berhubungan dengan pecaruan (semacam penyajian sesajen untuk bhuta yadnya) yang dilaksanakan sehari sebelum hari raya Nyepi, yang ditujukan untuk bhuta kala (kekuatan-kekuatan jahat/gelap). Bhuta kala digambarkan sebagai kekuatan-kekuatan jahat/gelap dan menyeramkan yang sering menggangu aktivitas manusia termasuk pada hari raya Nyepi.

Suasana yang diciptakan pada saat pengarakan Ogoh-ogoh, yang identik dengan suasana menyeramkan, mendorong terjadinya konflik-konflik (hal negatif) demikian, namun ini hanya berlangsung pada saat pengarakan Ogoh-ogoh saja. Hal ini, sesuai dengan pengertian bhuta kala yang memiliki sifat-sifat negatif, yang sering mengganggu segala aktivitas manusia.

Berdasarkan fenomena tersebut Ogohogoh dijadikan rangkaian pada perayaan hari raya Nyepi di Desa Pepuro Barat, karena Ogohogoh dapat merepresentasikan segala kegiatankegiatan yang berhubungan dengan ritual keagamaan masyarakat suku Bali yang ada di Desa Pepuro Barat, terkhususnya perayaan hari raya Nyepi tersebut.

Sesuai dengan yang dimaksud oleh Clifford Geertz, Agama merupakan sebuah sistem simbol-simbol yang berlaku untuk menetapkan suasana hati dan motivasi-motivasi yang kuat, yang meresapi, yang tahan lama dalam diri manusia dengan merumuskan konsep-konsep mengenai suatu tatanan umum eksistensi dan membungkus konsep-konseep ini dengan semacam pancaran faktualitas, sehingga suasana hati dan motivasi-motivasi tampak khas realistis (Susanto, 1992: 5).

\section{Eksistensi Tradisi Ogoh-Ogoh Dalam Rangkaian Perayaan Hari Raya Nyepi Di Desa Pepuro Barat Kecamatan Wotu Kabupaten Luwu Timur}

Tradisi Ogoh-ogoh hingga saat ini dapat mempertahankan eksistensinya di Desa Pepuro Barat, karena tradisi Ogoh-Ogoh yang dibuat memiliki daya tarik yang kuat seperti memberikan kemeriahan, keseruan, keramaian, kesemarakan dan yang paling utama adalah dibuat berdasarkan fenomena yang terjadi pada masyarakat Pepuro Barat. Seperti pada tahun 1996, dibuat Ogoh-ogoh barong bangkung (seni pertunjuk berwujud barong babi), karena pada saat itu masyarakat dibuat bingung dan kacau dengan aturan adat yang berlaku pada saat itu. sama halnya dengan barong bangkung yang identik dengan tanpa arah dan tujuan (kebingungan).

Pada tahun 1998, dibuat Ogoh-ogoh rangda yang menggendong tuyul, karena pada saat itu masyarakat diresahkan dengan hilangnya 
uang mereka secara tiba-tiba, baik yang sudah disimpan di lemari ataupun tempat tersembunyi lainnya. Rangda merupakan ratu dari para leak, yang memimpin para leak, dan tuyul secara umum sering dikategorikan mahkluk halus yang sering digunakan untu pesugihan, dengan cara mencuri uang manusia dan kemudian diberikan kepada tuannya. Dalam konteks ini, tuyul diibaratkan sebagai antek-antek dari rangda tersebut.

Pada tahun 2009, ketika balapan motor dan trek-trekan (gas-gas motor dengan knalpot bersuara besar) menjadi trend dan perbincangan yang menarik, maka dibuatlah Ogoh-ogoh yang sedang menaiki motor cross namun tetap menonjolkan ekspresi seramnya. Ini menunjukan bagaimana tradisi Ogoh-ogoh tetap eksis di Desa Pepuro Barat dan tetap bertahan hingga saat ini. Meski ekspresi dalam setiap pembuatan Ogoh-ogoh tetap sama dari tahun ke tahun, namun tidak demikian dengan bentuknya, dimana mengambil cerita kehidupan masyarakat pada saat itu.

Makna Simbolik Tradisi Ogoh-Ogoh Dalam Rangkaian Perayaan Hari Raya Nyepi Di Desa Pepuro Barat Kecamatan Wotu Kabupaten Luwu Timur

Tradisi Ogoh-ogoh bagi masyarakat Suku Bali yang ada di Desa Pepuro Barat bermakna sebagai keseimbangan antara sisi negatif dan positif dalam diri manusia. Keseimbangan yang dimaksud adalah keadaan dimana antara sisi positif dan negatif perbuatan manusia berada pada kondisi yang sama atau mirip. Sisi negatif tidak diharapkan hilang dari diri manusia, namun sebaliknya tetap dipertahankan dengan kadar yang sama/mirip dengan sisi positif. Sehingga sisi negatif (bhuta kala) tidak dihapuskan/dihilangkan tapi dinetralkan.

Hal ini dapat terlihat pada gaya atau ekspresi Ogoh-ogoh di Desa Pepuro Barat yang selalu dibuat menyeramkan. Ogoh-ogoh dibuat demikian untuk menggambarkan sifat-sifat bhuta kala yang buruk, jahat, dan gelap (negatif). Sehingga tidak jarang juga terjadi pertengkaran antar pengarak Ogoh-ogoh, atau masyarakat terluka diakibatkan terkena bambu atau terjatuh di got. Semua bagian tersebut disebabkan oleh suasana yang tercipta dari tradisi Ogoh-ogoh ini.

Namun di sisi lain, Ogoh-ogoh juga menciptakan hal-hal yang baik (positif) seperti terpupuknya rasa persatuan pada saat gotongroyong membuat dan mengarak Ogoh-ogoh (karena ogoh-ogoh tidak bisa dibuat dan diarak sendiri). Hal ini seperti ibarat memperbaiki dan juga merusak pada saat yang bersamaan. Meski demikian tidak membuat masyarakat suku Bali yang ada di Desa Pepuro Barat berhenti melakukan tradisi ini, justru masyarakat semakin antusias melaksanakannya setiap tahun.

Selain itu, kebudayaan suku Bali memiliki integrasi yang kuat dengan ajaran agama Hindu, termasuk tradisi Ogoh-ogoh. sehingga tradisi ini tidak lepas dari pemahaman agama. Salah satunya yaitu keyakinan dengan adanya tri loka atau 3 (tiga) tingkatan alam semesta, yaitu alam bhur, bvah, dan svah. Ketiga alam tersebut adalah alam para bhuta, manusia dan dewa. Hubungan antara ketiga alam ini diharapkan dapat seimbang, antara satu dengan lainnya. Hal ini terwujud pada penghargaan (upakara) yang dilakukan masyarakat suku bali yang ada di Desa Pepuro Barat, tidak hanya terhadap para dewa (unsur positif), tetapi juga kepada para bhuta (unsur negatif).

Hal ini sesuai dengan teori Clifford Geertz bahwa, budaya adalah keberaturan dari sistem makna dan simbol, yang dengan menggunakan makna dan simbol tersebut individu-individu mendefenisikan dunia mereka, mengekspresikan perasaan-perasaan mereka dan membuat penilaian terhadap diri mereka.

Demikian pula yang terjadi pada masyarakat suku Bali yang ada di Desa Pepuro Barat, bagi mereka makna tradisi Ogoh-ogoh adalah menjaga keseimbangan antara sisi positif dan negatif yang ada dalam diri manusia. Dimana sisi-sisi ini mereka gunakan untuk mendefenisikan kehidupan mereka, mengekpresikan perasaan-perasaan mereka dan pada akhirnya memberi penilaian terhadap diri mereka sendiri.

\section{SIMPULAN DAN SARAN}

Berdasarkan hasil penelitian yang diperoleh dapat disimpulkan bahwa Ogoh-ogoh dijadikan rangkaian dari pada perayaan hari raya Nyepi di Desa Pepuro Barat, karena Ogoh-ogoh dapat merepresentasikan atau mengekspresikan segala kegiatan-kegiatan yang berhubungan dengan ritual keagamaan masyarakat suku Bali yang ada di Desa Pepuro Barat, terkhususnya perayaan hari raya Nyepi tersebut. 
Ogoh-ogoh dapat mempertahankan eksistensinya di Desa Pepuro Barat, karena Ogoh-ogoh yang dibuat memiliki daya tarik yang kuat seperti memberikan kemeriahan, keseruan, keramaian, kesemarakan dan dibuat berdasarkan fenomena yang terjadi pada masyarakat Pepuro Barat.

Ogoh-ogoh bagi masyarakat suku bali yang ada di Desa Pepuro Barat Kecamatan Wotu Kabupaten Luwu Timur bermakna menjaga keseimbangan antara sisi positif dan negatif yang ada dalam diri manusia.

Berdasarkan dari hasil penelitian dan pembahasan di atas peneliti memiliki beberapa saran yaitu, pertama ditujukan pada masyarakat Suku Bali yang ada di Desa Pepuro Barat, agar selalu meminimalisir potensi terjadinya konflik bukan hanya pada saat pengarakan Ogoh-ogoh, tetapi juga sebelum pengarakan tersebut dilaksanakan. Kedua, Meski bukan tradisi yang wajib, namun Ogoh-ogoh sudah menjadi hal yang penting dalam kehidupan masyarakat Suku Bali yang ada di Desa Pepuro Barat sampai saat ini, sehingga perlu dilestarikan keberadaannya dan terakhir ditujukan kepada Pemerintah, wacana pawai Ogoh-ogoh yang akan dilaksanakan Pemerintahan Luwu Timur, hendaknya terlebih dahulu dilakukan pengkajian secara lebih mendalam, sehingga nantinya Tradisi Ogoh-ogoh selain menjadi pengekspresian diri masyarakat suku Bali, disisi lain juga dapat menjadi sarana edukasi.

\section{DAFTAR RUJUKAN}

Rahim, Abdul Rauf \& M. Saleh Madjid. 2012. Sejarah Indonesia Lama 1 Zaman Purba. Makassar: Rayhan Intermedia.

Agussalim, A.M. 2008. Ilmu Sosial Budaya Dasar. Makassar: Program Studi Sosiologi FIS-UNM Makassar.

Na'im \& Syaputra. 2010. Kewarganegaraan, Suku Bangsa, Agama, dan Bahasa Sehari-hari Penduduk Indonesia. Badan Pusat Statistik.

Arcana, Putu Fajar. 2007. Surat Merah Untuk Bali.Yogyakarta: Galangpress.

Koentjaraningrat. 2010. Manusia dan Kebudayaan di Indonesia. Jakarta: Djambatan.

Widnyani, Nyoman. 2012. Ogoh-ogoh Fungsi dan peranannya dimasyarakat dalam mewujudkan Generasi Emas Umat Hindu. Surabaya: Paramita.
Widana, I Gusti Ketut. 2016. Ogoh-ogoh Kapitalisasi Religi ditataran Materi. Denpasar: Pustaka Bali Post.

Susanto, Budi. 1992. Tafsir Kebudayaan. Yogyakarta: Kanisius. 